\title{
Educating Dental Students About Eating Disorders: Perceptions and Practice of Interprofessional Care
}

\author{
Katherine M. Frimenko, DDS; Carol Anne Murdoch-Kinch, DDS, PhD; \\ Marita R. Inglehart, Dr phil habil
}

Abstract: Providing care for patients with eating disorders (EDs) requires an interprofessional care (IPC) approach. The aims of this study were to assess dental students' ED- and IPC-related educational experiences, perceptions of preparedness for ED-related communication with patients and providers, and attitudes related to an IPC approach to ED. Relationships among perceptions of education, preparedness, attitudes, and characteristics (e.g., year in program and family members in other health care fields) were also explored. Of the 440 University of Michigan students invited to participate, 339 completed the survey (77\% response rate). A total of 257 students from another 21 dental schools completed the web-based survey, but their response rates could not be computed because it is unknown how many academic deans at the other 65 schools forwarded the recruitment email to their students. In the combined results, the students did not evaluate their ED- and IPC-related clinical education positively (mean=1.33 on scale from $1=$ least to $3=$ =most education), with first-year students (D1) reporting the least and fourth-year students (D4) the most educational experiences (D1: 1.08, D2: 1.16, D3: 1.42, D4: 1.59; $<<0.001$ ). While the students did not perceive themselves well prepared to talk with patients about mental health/ED, they reported feeling better prepared for IPC-related communication: on scale from $1=$ least to $5=$ most prepared, mean (patient) $=2.94 \mathrm{vs}$. mean $(\mathrm{IPC} /$ provider $)=3.61 ; \mathrm{p}<0.001$. All the students had mean positive attitudes towards dental professionals' ED-related responsibilities and related IPC considerations. The more education these students reported, the more prepared they perceived being and the more positive their attitudes. The more family members in health professions the students had, the better prepared they reported feeling to communicate with patients and providers from other disciplines about EDs. However, the finding that even the fourth-year students did not evaluate their ED- and IPC-related clinical education positively deserves attention. Educating students about EDs with an IPC approach could ensure better professional preparedness in this context.

Dr. Frimenko is a General Practice Resident, The Ohio State University; Dr. Murdoch-Kinch is the Dr. Walter H. Swartz Professor of Integrated Special Care Dentistry, Associate Dean for Academic Affairs, and Clinical Professor of Dentistry, Department of Oral and Maxillofacial Surgery/Hospital Dentistry, University of Michigan School of Dentistry; and Dr. Inglehart is Professor, Department of Periodontics and Oral Medicine, School of Dentistry and Adjunct Professor, Department of Psychology, College of Literature, Science \& Arts, University of Michigan. Direct correspondence to Dr. Carol Anne Murdoch-Kinch, University of Michigan School of Dentistry, 1011 N. University Street, Ann Arbor, MI 48109-1078; 734-763-5651; camurdoc@umich.edu.

Keywords: dental education, bulimia, anorexia, eating disorders, patient-provider communication, health education, behavioral science, interprofessional care, interprofessional education, interdisciplinary health team

Submitted for publication 11/22/16; accepted 5/30/17

doi: 10.21815/JDE.017.090

$\mathrm{E}$ ating disorders (EDs) can be described as "a group of psychopathological disorders affecting patient relationship with food and his/ her own body, which manifests through disordered or chaotic eating behavior" "and are considered a major public health issue in the U.S. today. ${ }^{2-6}$ The International Classification of Diseases (ICD-10) has identified anorexia nervosa (AN) and bulimia nervosa $(\mathrm{BN})$ as the two main ED diagnoses. ${ }^{7}$ Potential effects of the disorders can be severe. The mortality rate associated with $\mathrm{AN}$ is the highest among all mental health disorders, ${ }^{7-9}$ and an epidemiological study reported that $\mathrm{AN}$ and $\mathrm{BN}$ combined "rank as the 12th leading cause of disability adjusted life years (DALYs) in females aged 15-19 years in highincome countries." ${ }^{10}$ In fact, self-induced starvation associated with AN can result in adverse effects on and atrophy of multiple physiological systems and organs including the heart, brain, liver, intestines, kidneys, and muscles. ${ }^{11}$ EDs can also have severe consequences for patients' oral health such as lesions of the mucosa, periodontium, and dentition and symptoms such as xerostomia and oral pain. .,12,13 $^{2}$ Not only do such manifestations often require dental attention, but the oral signs and symptoms of EDs make members of the oral health care team key in the early detection of EDs. ${ }^{14-16}$

Early detection and intervention are important for the safe treatment and recovery of patients with EDs to avoid and/or minimize oral health sequellae..$^{2,16,17}$ Identification of symptoms of EDs and appropriate referral for care are therefore important 
responsibilities of oral health care providers. ${ }^{2,17}$ Given the complex, multifaceted nature of EDs, an optimal approach to care for a patient with an ED should involve an interdisciplinary team approach in which mental health professionals, physicians, dietitians and/or nutritionists, and other health care providers provide specialized aspects of patients' care in a team-based approach, with the ultimate goal of helping patients restore their health. ${ }^{18}$ Dental care is one important aspect of such interprofessional care (IPC) for patients with EDs; however, many health care providers are unaware of the importance of including dentists in these patients' IPC..$^{15}$ In 2005, DeBate et al. argued that one reason for this lack of interdisciplinary communication might be that dental professionals are not "prepared to treat, identify, and refer patients with EDs." 16 This lack of ED-related education could result in an exclusion of dental care providers from IPC for these patients..$^{19,20}$

More than a decade later, two new Commission on Dental Accreditation (CODA) standards may provide a basis for revisiting the question of whether dental students are optimally educated about providing IPC for patients with EDs. ${ }^{21}$ Standard 2-19 states that "Graduates must be competent in communicating and collaborating with other members of the health care team to facilitate the provision of health care," and Standard 2-24 states that "Graduates must be competent in assessing the treatment needs of patients with special needs." In response to Standard 2-19, U.S. dental schools have been adding interprofessional education (IPE) to their curricula. ${ }^{22-24}$ One question, however, is whether dental students receive an education that specifically prepares them for participating in IPC when they encounter patients with special health care needs such as patients with EDs. While web-based learning opportunities and modules have been designed and implemented in predoctoral curricula to further educate students about IPE and the role of an oral health care provider in care for $\mathrm{EDs},{ }^{2,17}$ research is needed to determine whether dental students experience their education about an IPC approach to EDs as optimally preparing them for providing care for patients with EDs.

In addition to determining how prepared future dentists are about participating in IPC for patients with EDs, assessing students' attitudes is also of interest because these attitudes may determine how motivated future dentists will be to engage in IPC for these patients. Interestingly, DeBate et al. found that most oral health care providers in their study had a sense of ethical and moral obligation to do so; however, their attitudes about their perceived selfefficacy affected how likely they were to engage in IPC for EDs. ${ }^{2}$

The aims of this study were to assess dental students' ED- and IPC-related educational experiences, perceptions of preparedness for ED-related communication with patients and providers, and attitudes related to an IPC approach to ED. Special emphasis was placed on assessing whether students' perceptions of ED- and IPC-related education, preparedness, and attitudes were more positive in the last year of dental school than earlier in their education. The relationships between students' perceptions of their ED- and IPC-related education and of their preparedness, attitudes, and personal/ professional characteristics (e.g., having vs. not having volunteered in a medical setting; having vs. not having family members in other health care fields) were also explored. It was expected that students with volunteer experiences in medical settings and/ or from families with medical/mental/other health care providers would have more positive IPC-related responses than students who had volunteered only in dental settings and/or had no family members in other health professions.

\section{Methods}

This study was determined to be exempt from oversight by the Institutional Review Board for the Health and Behavior Sciences at the University of Michigan on July 9, 2015 (HUM\#00103855). The population invited to participate in the study were all dental students in all four years at the University of Michigan School of Dentistry (who completed both paper and online surveys), followed by all dental students in all four years at all 65 other U.S. dental schools in 2016 when the study was conducted (these students were invited to participate via the academic deans at their schools, who were asked to forward the email invitation to their students).

At the University of Michigan School of Dentistry, paper surveys were handed out at the end of regularly scheduled classes, and students returned these surveys anonymously to the research team. In addition, a recruitment email with a web-link to an anonymous web-based survey was sent to all fourthyear students (D4) at this school because there was a high likelihood that these seniors were not present in the classroom when the data were collected due to extensive absences from campus for community- 
based dental education rotations. The academic deans of the other 65 U.S. dental schools were identified using the American Student Dental Association (ASDA) website ${ }^{25}$ and were contacted with an email that informed them about the study and asked them to forward a recruitment email with a web-link to the anonymous survey to all their predoctoral dental students.

The survey development began with identification of the three main constructs of interest. Part 1 focused on students' demographic and family characteristics and experiences that may affect the way they responded to the educational and attitudinal questions. Indicators relevant for this construct were personal, educational, and health profession-related characteristics such as gender, year in dental school, types of volunteer activities prior to dental school, and having family members who were medical, mental, or other health care providers.

Part 2 of the survey consisted of questions concerning students' perceptions of their ED- and IPC-related educational experiences. We decided to ask these questions by type of setting: education received in a classroom-based (Part 2a) vs. clinical setting (Part 2b). Thus, Part 2a consisted of five questions about students' evaluations of the quantity of their classroom-based IPC-related education and six questions about their ED-related classroom-based education. Based on findings by DeBate and Tedesco that education about EDs is likely to be marginal in dental school curricula, ${ }^{19}$ we decided to use a threepoint rating scale for these 11 questions, ranging from $1=$ not at all to $3=$ very much. Part $b$ consisted of 11 clinic-based educational questions. Five of these questions were general IPC-related questions, and six were more specific IPC- and ED-related items. Again, based on considerations concerning the degree to which dental students might be educated about EDs, ${ }^{19}$ responses were on a three-point scale from $1=$ never to $3=$ often.

The third construct was concerned with students' ED- and IPC-related perceptions and beliefs in general (Part 3). Four questions asked how well the students felt prepared to talk with patients about various aspects of their health, and three questions asked how well prepared they felt to discuss mental health and ED-related findings with patients (Part $3 a)$. The second subset inquired how prepared students felt to talk with health care providers from other disciplines about these issues (six questions) (Part 3b). The four other subsets of questions were concerned with the students' ED- and IPC-related beliefs/attitudes. Three questions asked how much EDs are psychological, medical, or dental concerns (Part 3c); three questions inquired how much dental professionals should be involved in ED-related care (Part 3d); two questions asked how much professionals in other health care disciplines understand dental implications of EDs and have an interest in the patient's overall health (Part 3e); and four questions addressed how likely students were to refer patients to other providers and consider ED history as an oral health risk factor (Part 3f). The questions related to the third construct were all answered on five-point rating scales (from $1=$ not at all to $5=$ very much).

The first draft of the survey was reviewed by experts or specialists in oral medicine, academic affairs, interprofessional education, health psychology, and survey research and one senior dental student. These experts contributed substantially to finalizing the content and wording of the survey and to ensuring that the instrument had content validity.

The surveys submitted on paper were entered into SPSS for Windows, Version 22 (IBM Corp., Armonk, NY, USA). The web-based responses were downloaded from the UM Lessons website as an Excel file and imported into the same SPSS data file. Descriptive statistics such as frequency distributions, percentages, means, and standard deviations were used to provide an overview of the responses. The 22 education-related questions related to the second construct were factor analyzed (Extraction Method: Principal Component Analysis; Varimax Rotation) to determine underlying factors. Items with factor loadings $>0.40$ on particular factors were used to create indices by averaging the responses to the items loading on each factor. The factor analyses results led to four subscales. To determine the reliability of these subscales, Cronbach's alpha inter-item consistency coefficients were computed. These coefficients ranged from 0.787 to 0.877 , indicating acceptable to very good reliability. A second factor analysis with the 13 items about students' preparedness resulted in three subscales, which had good to very good interitem consistency (alphas 0.828 to 0.927 ). A final factor analysis with the 14 ED- and IPC-related beliefs/ attitude items resulted in four subscales, of which three had acceptable to good inter-item consistency/ reliability. Univariate analyses of variance were used to test whether the average mean index scores for students across the four years differed significantly from each other and if the first- and second-year cohorts had less positive responses than the third- and fourth-year cohorts. Contingency coefficients were 
computed to test the hypotheses that there would be a relationship for each single item between the students' year in school and their educational and construct three-related responses.

Pearson correlation coefficients were computed to determine relationships between the students' educational experiences indices, preparedness, and ED- and IPC-related attitudinal indices and their year in dental school and sum of family members in the health professions. In addition, independent sample t-tests were used to determine if the mean indices of students who had never volunteered in a medical or mental health setting were significantly different from those of students who had volunteered in these settings prior to beginning dental school.

\section{Results}

Of the total 440 dental students at the University of Michigan invited to participate, 339 completed the survey, for a response rate of $77 \%$. A total of 257 students from another 21 dental schools completed the web-based survey. It is unknown how many of the academic deans at the other 65 dental schools forwarded the recruitment email to their students, so the response rate for those schools could not be computed. In total, there were 596 students at 22 schools who participated in the study. Responses from the University of Michigan and the other 21 schools were combined for the analyses.

The 596 participating students were from all four years of the dental curriculum (D1: 109; D2: 164; D3: 183; D4: 138) (Table 1). Approximately $50 \%$ of them were male, and the majority were European American (71\%), followed by $14 \%$ Asian American. The responding students ranged in age from 23 to 43 years with an average age of 25.57 years. Prior to attending dental school, these students had most frequently volunteered in dentistry $(74 \%)$, with $23 \%$ having volunteered in medicine, $2 \%$ in mental health settings, and 3\% in other health care settings such as pharmacy, nursing, or health administration. When asked if they had a family member in a health care field, $29 \%$ reported having a family member who was an oral health care provider, $6 \%$ a family member who worked as a mental health care provider, and $45 \%$ a family member in another health care discipline.

Table 2 provides an overview of these students' perceptions of how much, in the four years of the curriculum, they had learned in classroom-based settings about ED (six questions) and IPC (five ques-
Table 1. Demographic and educational characteristics of students in study $(\mathrm{N}=596)$

\begin{tabular}{lcc} 
Characteristic & Number & Percentage \\
\hline Gender & & \\
Male & 295 & $50 \%$ \\
Female & 298 & $50 \%$ \\
Race/ethnicity & & \\
$\quad$ European American & 416 & $71 \%$ \\
Asian American & 83 & $14 \%$ \\
Arab & 24 & $4 \%$ \\
Indian & 14 & $2 \%$ \\
Black & 12 & $2 \%$ \\
Hispanic/Latino & 12 & $2 \%$ \\
American Indian & 6 & $1 \%$ \\
Bi/multiracial & 15 & $3 \%$ \\
Other & 1 & $0.2 \%$ \\
Age in years & Mean=25.57 & SD $=3.08$ \\
$\quad$ & & Range: $23-43$ \\
Number of responses from & Mean=27 & Range: 3 to 339 \\
22 schools: mean and range & & \\
Number of paper \& pencil & Paper & Web \\
vs. web surveys & & \\
Home school & 329 & 10 \\
Other schools & 0 & 257 \\
Year in program & & \\
D1 & & \\
D2 & 109 & $18 \%$ \\
D3 & 164 & $28 \%$ \\
D4 & 183 & $31 \%$ \\
Prior to dental school, \\
I volunteered or worked \\
in the field of:
\end{tabular}

Note: Some respondents skipped demographic questions; only the respondents with volunteer experience or family members in the health professions answered those questions. Average responses of the ten D4 students at the home school (University of Michigan) who provided web-based responses and the 68 D4 students at the home school who provided paper \& pencil responses did not differ for 47 of the 48 items, so the two groups' data were combined.

tions) and how often they had engaged in clinical behavior in general (four questions) and in ED- and IPC-related clinical behavior specifically (six questions). Univariate analyses of variance were used to test the hypothesis that the average indices of the four subscales would differ systematically with the means of the first- and second-year cohorts being lower than the means of the third- and fourth-year cohorts. This hypothesis was supported by the data. 


\section{Table 2. Respondents' eating disorder (ED) and interprofessional care (IPC) experiences in classroom and clinical settings, by year in dental school (total student $\mathrm{N}=596$ )}

\begin{tabular}{|c|c|c|c|c|c|}
\hline Item & D1 & $\mathrm{D} 2$ & D3 & D4 & $\begin{array}{c}\text { CC } \\
\text { p-value }\end{array}$ \\
\hline \multicolumn{6}{|l|}{ Classroom-based education about EDs: how much have you ${ }^{a}$} \\
\hline Learned about potential oral signs and symptoms of EDs? & 1.93 & 2.34 & 2.56 & 2.47 & $0.34 * *$ \\
\hline Learned about potential systemic effects of EDs? & 1.74 & 2.09 & 2.38 & 2.26 & $0.35^{* *}$ \\
\hline Learned about what treatment for an ED may entail? & 1.54 & 1.67 & 2.05 & 1.91 & $0.29 * *$ \\
\hline $\begin{array}{l}\text { Received instruction on addressing patients who present with oral signs } \\
\text { and/or symptoms of an ED? }\end{array}$ & 1.50 & 1.87 & 2.10 & 2.04 & $0.31^{* *}$ \\
\hline Participated in a classroom simulation on addressing patients with EDs? & 1.24 & 1.27 & 1.72 & 1.54 & $0.29 * *$ \\
\hline $\begin{array}{l}\text { Learned about a protocol for referring patients who present with signs } \\
\text { and symptoms of ED? }\end{array}$ & 1.26 & 1.39 & 1.73 & 1.64 & $0.29^{* *}$ \\
\hline Classroom-based education about EDs index (Cronbach's alpha=0.877) & 1.53 & 1.76 & 2.09 & 1.97 & $* * c$ \\
\hline \multicolumn{6}{|l|}{ Classroom-based IPC: how much have you ${ }^{a}$} \\
\hline Learned about other health care professions? & 1.99 & 2.02 & 2.23 & 2.20 & $* *$ \\
\hline Practiced writing a referral to a health profession outside of dentistry? & 1.14 & 1.37 & 1.92 & 2.21 & $0.51 * *$ \\
\hline Worked on a team with students from other health professions? & 1.43 & 1.41 & 1.67 & 2.20 & $0.40^{* *}$ \\
\hline Practiced problem-solving with students from other health care disciplines? & 1.44 & 1.35 & 1.65 & 2.13 & $0.40^{* *}$ \\
\hline Classroom-based IPC index (Cronbach's alpha=0.787) & 1.50 & 1.54 & 1.87 & 2.18 & $* * c$ \\
\hline \multicolumn{6}{|l|}{ Classroom-based education: single item related to IPE } \\
\hline Learned from an instructor outside the field of dentistry? & 2.43 & 2.57 & 2.35 & 2.38 & $0.20^{* *}$ \\
\hline \multicolumn{6}{|l|}{ Clinic-based education, introductory issues: how often have you ${ }^{b}$} \\
\hline Written a patient referral? & 1.08 & 1.16 & 2.09 & 2.37 & $0.60^{* *}$ \\
\hline Asked a patient about his/her physical health? & 1.20 & 2.20 & 2.89 & 2.88 & $0.65^{* *}$ \\
\hline Asked a patient about his/her mental health? & 1.14 & 1.48 & 2.34 & 2.47 & $0.58^{* *}$ \\
\hline Asked a patient about his/her diet and/or eating habits? & 1.14 & 1.94 & 2.60 & 2.55 & $0.57^{* *}$ \\
\hline Consulted with a health care professional outside of dentistry? & 1.12 & 1.29 & 1.89 & 2.27 & $0.55^{* *}$ \\
\hline Introductory clinical education index (Cronbach's alpha=0.872) & 1.13 & 1.61 & 2.36 & 2.51 & $* * c$ \\
\hline \multicolumn{6}{|l|}{ Clinic-based education, ED and IPC issues: how often have you ${ }^{b}$} \\
\hline Worked on a team with students of other health professions? & 1.10 & 1.21 & 1.48 & 1.80 & $0.39 * *$ \\
\hline Devised a treatment plan that involved other health professionals? & 1.10 & 1.23 & 1.56 & 1.80 & $0.39 * *$ \\
\hline Solved a problem with students from other health professions? & 1.10 & 1.18 & 1.36 & 1.69 & $0.36^{* *}$ \\
\hline Treated a patient who shows signs and/or symptoms characteristic of an ED? & 1.06 & 1.15 & 1.44 & 1.56 & $0.34^{* *}$ \\
\hline Participated in a clinical simulation on addressing patients with EDs? & 1.06 & 1.13 & 1.53 & 1.46 & $0.35^{* *}$ \\
\hline Referred a patient to a mental health care provider? & 1.06 & 1.05 & 1.15 & 1.20 & $0.18^{*}$ \\
\hline ED- and IPC-related clinical education index (Cronbach's alpha=0.870) & 1.08 & 1.16 & 1.42 & 1.59 & $* * c$ \\
\hline \multicolumn{6}{|c|}{$\begin{array}{l}\text { a Response options ranged from } 1=\text { not at all to } 3=\text { very much. } \\
\text { besponse options ranged from } 1=\text { never to } 3=\text { frequently. } \\
\text { 'The } p \text {-values for the comparison of the average index scores for the four years refer to the results of a univariate analysis of variance. } \\
{ }^{*} p<0.01 ; * * p<0.001\end{array}$} \\
\hline
\end{tabular}

In addition, contingency coefficients were computed to test this hypothesis for each single item. Again, the results supported this hypothesis. Overall, the students responded most positively that they had learned about the potential oral signs and symptoms of EDs and about potential systemic effects of eating disorders. However, overall their ED-related classroom-based education was just below the middle point of the scale, with D1s and D2s giving less positive responses than D3s and D4s.

The same pattern of responses was also found in the classroom-based IPC-related responses (classroom-based IPC index; Cronbach's alpha $=0.787$ ).
Again, the students in the earlier cohorts reported less education than those in the later cohorts. Overall, the IPC-related education was not perceived very positively. While the average frequencies of having engaged in general clinical activities (introductory clinical education index; Cronbach's alpha $=0.872$ ) were on average quite high for D3s and D4s and lower for D1s and D2s, the average ED- and IPCrelated clinical education indices (Cronbach's alpha $=0.870$ ) were quite low, indicating a low level of this type of clinic-based education in all four years of the curriculum. 
Table 3 provides information about how prepared the responding students felt to talk with patients and with other health care professionals from different disciplines about patients' oral, mental, and general health issues. Overall, these students reported feeling very well prepared on average to talk with patients about oral health issues (on scale from $1=$ not at all to $5=$ very well prepared, mean $=4.36$ ) and even about patients' diet (mean=4.00) and systemic health issues (mean $=3.83$ ). They reported feeling less well prepared to talk with patients about referring them to a provider in another health care discipline (mean=3.52). Again, the students reported feeling increasingly well prepared as they progressed through the curriculum. However, they reported feeling less well prepared on average to talk with patients about their mental health (mean=2.99), clinical findings indicative of an ED (mean=3.16), and general treatment options for EDs (mean=2.68). Even in the D4 year, the students did not indicate on average that they felt well prepared to talk with patients about these issues. When asked how well prepared they felt to talk with health care professionals from another discipline, the students reported feeling on average well prepared to talk with them about patients' oral health (mean $=4.19$ ), slightly well prepared to talk with them about patients' systemic health (mean $=3.63$ ), but least well prepared to talk with them about patients' mental health issues (mean=3.05).

Table 4 provides an overview of the students' attitudes and opinions about EDs and IPC. When asked how much EDs were a psychological, medical, and dental concern, the students in all four years of the curriculum on average indicated that EDs were much/very much a concern in each of these three respects. When asked how much dental professionals should be involved in identifying a patient with an $\mathrm{ED}$, all four cohorts responded on average that they should be much/very much involved. However, when asked how much they should be involved in patients' treatment for an ED and in patients' long-term stability post-treatment for an ED, the answers were on average only slightly positive. Overall, students in the four years did not differ from each other in their responses to nearly all of these questions.

When asked how likely they were to refer a patient to a medical, dental, or mental health professional, the students in all four years of the dental school curriculum reported feeling that they were very likely to refer a patient to a medical or dental

Table 3. Respondents' perceived preparation to communicate with patients and health care professionals from other disciplines, by year in dental school (total student $\mathrm{N}=596$ )

\begin{tabular}{|c|c|c|c|c|c|}
\hline Item & D1 & D2 & D3 & D4 & $\begin{array}{c}\text { CC } \\
\text { p-value }\end{array}$ \\
\hline \multicolumn{6}{|l|}{ How prepared do you feel to talk with a patient about } \\
\hline His/her oral health? & 3.27 & 4.31 & 3.65 & 4.87 & $0.54^{*}$ \\
\hline His/her systemic health? & 3.10 & 3.65 & 4.02 & 4.35 & $0.44^{*}$ \\
\hline His/her diet? & 3.29 & 3.93 & 4.22 & 4.33 & $0.38^{*}$ \\
\hline Referring him/her to another health care discipline? & 3.00 & 3.31 & 3.69 & 3.96 & $0.37^{*}$ \\
\hline $\begin{array}{l}\text { Patient oral and general health communication preparedness index } \\
\text { (Cronbach's alpha=0.878) }\end{array}$ & 3.16 & 3.80 & 4.15 & 4.37 & $*$ \\
\hline \multicolumn{6}{|l|}{ How prepared do you feel to talk with a patient about } \\
\hline His/her mental health? & 2.68 & 2.67 & 3.18 & 3.36 & $0.35^{*}$ \\
\hline Clinical findings suggestive of an eating disorder? & 2.53 & 2.98 & 3.48 & 3.46 & $0.40^{*}$ \\
\hline General treatment options for eating disorders? & 2.48 & 2.44 & 2.91 & 2.82 & $0.31 *$ \\
\hline Patient mental health communication preparedness index (Cronbach's alpha=0.828) & 2.56 & 2.70 & 3.19 & 3.21 & $*$ \\
\hline \multicolumn{6}{|l|}{$\begin{array}{l}\text { How prepared do you feel to talk with a health care professional from another } \\
\text { discipline about }\end{array}$} \\
\hline A patient's oral health? & 3.06 & 4.14 & 4.47 & 4.73 & $0.48^{*}$ \\
\hline A patient's systemic health? & 2.81 & 3.47 & 3.84 & 4.17 & $0.46^{*}$ \\
\hline A patient's mental health? & 2.64 & 2.88 & 3.21 & 3.36 & $0.31 *$ \\
\hline A patient's diet? & 3.03 & 3.74 & 4.12 & 4.26 & $0.41^{*}$ \\
\hline A multidisciplinary treatment plan? & 2.73 & 3.09 & 3.52 & 3.90 & $0.45^{*}$ \\
\hline Oral effects of eating disorders? & 2.63 & 3.48 & 3.95 & 4.07 & $0.44^{*}$ \\
\hline Interprofessional communication preparedness index (Cronbach's alpha=0.927) & 2.83 & 3.46 & 3.85 & 4.07 & $*$ \\
\hline
\end{tabular}

Note: Response options ranged from $1=$ not at all to $5=$ very much.

${ }^{*} \mathrm{p} \leq 0.001$ 


\begin{tabular}{|c|c|c|c|c|c|}
\hline Item & D1 & D2 & D3 & D4 & $\begin{array}{c}C C \\
\text { p-value }\end{array}$ \\
\hline \multicolumn{6}{|l|}{ How much are EDs } \\
\hline A psychological concern? & 4.60 & 4.64 & 4.73 & 4.71 & $0.18^{*}$ \\
\hline A medical concern? & 4.59 & 4.62 & 4.63 & 4.66 & ns \\
\hline A dental concern? & 4.49 & 4.53 & 4.51 & 4.55 & ns \\
\hline Understanding ED index (Cronbach's alpha=0.843) & 4.56 & 4.60 & 4.62 & 4.64 & 4.61 \\
\hline \multicolumn{6}{|l|}{ How much should dental professionals be involved in } \\
\hline Identifying a patient with an ED? & 4.39 & 4.44 & 4.48 & 4.43 & ns \\
\hline A patient's treatment for an ED? & 3.71 & 3.53 & 3.75 & 3.55 & ns \\
\hline A patient's long-term stability post-treatment for an ED? & 3.76 & 3.58 & 3.90 & 3.84 & ns \\
\hline Dental professionals' ED-related responsibilities (Cronbach's alpha=0.792) & 3.96 & 3.85 & 4.04 & 3.95 & ns \\
\hline \multicolumn{6}{|l|}{ How much do professionals in other health care disciplines } \\
\hline Understand the dental implications of EDs? & 3.26 & 3.17 & 3.06 & 3.14 & ns \\
\hline Have an interest in a patient's comprehensive health? & 3.94 & 3.92 & 3.85 & 3.97 & ns \\
\hline Other professionals' oral health-related concerns (Cronbach's alpha=0.605) & 3.59 & 3.54 & 3.45 & 3.56 & ns \\
\hline \multicolumn{6}{|l|}{ How likely are you to } \\
\hline Refer a patient to a medical health professional? & 4.71 & 4.24 & 4.31 & 4.40 & ns \\
\hline Refer a patient to another dental professional or specialist? & 3.99 & 4.17 & 4.42 & 4.54 & $0.27^{* *}$ \\
\hline Refer a patient to a mental health professional? & 3.70 & 3.60 & 3.64 & 3.39 & $0.20^{*}$ \\
\hline Consider a patient's ED history when determining oral health risk factors? & 4.16 & 4.19 & 4.37 & 4.29 & ns \\
\hline Anticipated interprofessional considerations (Cronbach's alpha=0.736) & 4.00 & 4.05 & 4.19 & 4.16 & ns \\
\hline
\end{tabular}

professional. However, the D1 students were less likely to indicate they would refer the patient to another dental professional or specialist than the students in later years of the curriculum. On average, students in all four years were less likely to refer a patient to a mental health professional, but they were very likely in all four years to consider a patient's ED history when determining oral health risk factors.

Finally, two questions asked the students how much professionals in other health care disciplines understand the dental implications of EDs and have an interest in patients' comprehensive health. The average responses of the students did not differ across the four years in response to these questions. All of these students reported thinking that other health care professionals do not understand the dental implications of EDs well, but that other health care professionals do have an interest in patients' comprehensive health.

One important question was whether the students' perceived preparedness to communicate with patients and providers from other disciplines would be correlated with their classroom- and clinic-based educational experiences and their ED- and IPC-related attitudes. ED- and IPC-related classroom-based education was significantly correlated with the students' sense of being prepared to communicate with patients and providers from other disciplines (Table 5). In addition, the more prepared students reported feeling, the more positive their attitudes were.

One additional question was whether a structural factor (year in dental school) and two personal factors (number of family members who were health professionals and previous experiences in a medical and/or mental health setting) would be related to students' classroom- and clinic-based education, their sense of preparedness to communicate with patients and providers, and their attitudes/opinions about EDs and IPC. Both the year in dental school and the sum of family members in the health professions were significantly correlated with the students' classroom-based and clinical educational experiences and preparedness, but not with their ED- and IPC-related attitudes/opinions (Table 6). However, whether students had volunteered in a medical or mental health setting before dental school did not affect their mean responses concerning the degree of educational experiences, how well prepared they were, nor their attitudes. The only significant difference between dental students who had vs. had 
Table 5. Correlations between responding students' preparedness to communicate and their educational experiences and eating disorder (ED)/interprofessional care (IPC)-related attitudes/perceptions (total student $\mathrm{N}=596$ )

\begin{tabular}{|c|c|c|c|}
\hline Item/Index & $\begin{array}{l}\text { Students' Perceived } \\
\text { Patients About Oral } \\
\text { and General Health }\end{array}$ & $\begin{array}{l}\text { reparedness to C } \\
\text { Patients About } \\
\text { Mental Health }\end{array}$ & $\begin{array}{l}\text { mmunicate With } \\
\text { Providers from } \\
\text { Other Disciplines }\end{array}$ \\
\hline \multicolumn{4}{|l|}{ How prepared do you feel to talk with } \\
\hline Patients about oral and general health & 1 & $0.68^{*}$ & $0.80^{*}$ \\
\hline Patients about mental health & $0.68^{*}$ & 1 & $0.66^{*}$ \\
\hline Providers from other health care disciplines & $0.80^{*}$ & $0.66^{*}$ & 1 \\
\hline \multicolumn{4}{|l|}{ Educational indices } \\
\hline Classroom-based ED-related educational experiences & $0.41 *$ & $0.53 *$ & $0.45^{*}$ \\
\hline Classroom-based IPC-related educational experiences & $0.32 *$ & $0.35^{*}$ & $0.37 *$ \\
\hline Clinic-based general patient health-related experiences & $0.55^{*}$ & $0.37 *$ & $0.49^{*}$ \\
\hline Clinic-based ED- or IPC-related experiences & $0.33^{*}$ & $0.39 *$ & $0.34^{*}$ \\
\hline \multicolumn{4}{|l|}{ Attitudinal indices } \\
\hline Students' assessment of ED as health-related concerns & $0.24^{*}$ & $0.19 *$ & $0.26^{*}$ \\
\hline Dental professionals' ED-related responsibilities & $0.15^{*}$ & $0.32 *$ & $0.18^{*}$ \\
\hline $\begin{array}{l}\text { Students' perception of other health professionals' investment } \\
\text { in patient health }\end{array}$ & $0.14^{*}$ & $0.23 *$ & $0.20^{*}$ \\
\hline Students' self-reported likelihood to engage in IPC-related care & $0.37 *$ & $0.40^{*}$ & $0.37 *$ \\
\hline$* p<0.001$ & & & \\
\hline
\end{tabular}

not volunteered in medical and mental health settings was that volunteers on average believed more strongly that other health care professionals' oral health-related concerns were higher than did those students who had not volunteered in those settings.

\section{Discussion}

EDs are complex, multifaceted conditions that can have significant overall and oral health consequences that require treatment from a multidisciplinary team of health care professionals for optimal care. ${ }^{15,18}$ Dental providers can play a crucial role in identifying signs and symptoms of EDs and then contribute to IPC for patients with EDs. ${ }^{16}$ Educational researchers have thus stressed the importance of educating dental and dental hygiene students about EDs and an IPC-related approach to their treatment, ${ }^{19,20,24,26}$ a recommendation that is clearly consistent with CODA predoctoral dental standards 2-19 concerning IPE and 2-24 concerning services for patients with special health care needs. ${ }^{21}$

One question in this context is how predoctoral students in U.S. dental schools perceive their ED- and IPC-related classroom-based education and the frequency with which they engage in ED- and IPC-related clinical care. It is important to note that the survey used in our study did not ask students their perceptions of how well they were educated in order to be qualified about these issues and the study did not assess their knowledge in any other way such as exam grades or other instructor evaluations. Instead, the students merely reported their perceptions of their classroom-based ED- and IPC-related experiences and the frequencies with which they had been engaged in specific ED- and IPC-related clinical activities.

In addition, it is important to note that this study was not an evaluation of an educational intervention in one specific dental school. Instead, the objectives were to explore these constructs and the relationships among different constructs of interest. For example, we tested the hypotheses whether first- and second-year students perceived they had received less education and engaged less frequently in ED- and IPC-related activities than did those in the third and fourth years and whether the degree of having been exposed to family members in the health professions would result in more positive IPC-related attitudes. Data were therefore collected from students in 22 U.S. dental schools to provide a broader basis for generalizations. If data had only been collected from one particular dental school, idiosyncrasies of this educational system would have not allowed making any generalizations.

In addition, comparisons of the average single item plus index responses for the four classes separately plus for all students combined for the home school vs. the other 21 schools showed that the means differed significantly only for all four classes plus overall for one index-the classroom-based IPE 


\begin{tabular}{|c|c|c|c|c|}
\hline \multirow[b]{2}{*}{ Index } & \multirow{2}{*}{$\begin{array}{l}\text { Year in } \\
\text { Dental School }\end{array}$} & \multirow{2}{*}{$\begin{array}{c}\text { Family Members } \\
\text { in Health } \\
\text { Professions }\end{array}$} & \multicolumn{2}{|c|}{$\begin{array}{l}\text { Volunteered in Medical/ } \\
\text { Mental Health Setting }\end{array}$} \\
\hline & & & No & Yes \\
\hline \multicolumn{5}{|l|}{ Educational indices } \\
\hline Classroom-based education about ED index & $0.17 * * *$ & $0.32 * * *$ & 1.85 & 1.91 \\
\hline Classroom-based IPC education index & $0.12^{* *}$ & $0.47^{* * *}$ & 1.80 & 1.73 \\
\hline Introductory clinical education index & $0.11^{* *}$ & $0.78^{* * *}$ & 1.99 & 1.97 \\
\hline ED- and IPC-related clinical education index & $0.15^{* * *}$ & $0.41^{* * *}$ & 1.32 & 1.36 \\
\hline \multicolumn{5}{|l|}{ Indices: preparedness to communicate with } \\
\hline Patients about oral and general health & 0.08 & $0.45^{* * *}$ & 3.94 & 3.87 \\
\hline Patients about mental health & 0.06 & $0.26 * * *$ & 2.92 & 2.98 \\
\hline Providers from other health care disciplines & $0.09 *$ & $0.42^{* *}$ & 3.63 & 3.56 \\
\hline \multicolumn{5}{|l|}{ Attitudinal indices } \\
\hline Students' assessment of ED as health-related concerns & 0.04 & 0.05 & 4.61 & 4.60 \\
\hline Dental professionals' ED-related responsibilities index & -0.04 & 0.03 & 3.93 & 3.98 \\
\hline $\begin{array}{l}\text { Students' perceptions about other health care professionals' } \\
\text { investment in patient health }\end{array}$ & -0.02 & -0.03 & 3.47 & $3.68^{*}$ \\
\hline Students' self-reported likelihood to engage in IPC-related care & 0.01 & $0.10^{*}$ & 4.08 & 4.17 \\
\hline${ }^{*} \mathrm{p}<0.05 ;{ }^{* *} \mathrm{p}<0.01 ;{ }^{* * *} \mathrm{p}<0.001$ & & & & \\
\hline
\end{tabular}

index, for which the mean home school response was significantly lower than the mean other schools response - as well as for three single items of which two were part of the classroom-based IPE index. These results led to combining the data from the home school and the other schools for the analyses.

The data from this wide range of 22 schools showed that the responding third- and fourth-year students reported feeling educated about basic EDrelated issues such as the signs and symptoms of an ED and potential systemic effects of EDs. However, even students in the third and fourth years evaluated their IPC-related education about ED ("what treatment for an ED might entail" and "protocol for referring patients with signs and symptoms of ED") less positively. Their responses concerning clinic-based educational experiences also showed that their IPCrelated activities had focused primarily on general health and much less on mental health or specifically on ED. Students in the third and fourth years reported that they quite frequently asked patients about their physical health and wrote patient referrals, but were less likely to inquire about mental health concerns and rarely referred a patient to a mental health care provider. These responses point to the importance of considering IPC with a broader perspective that goes beyond collaboration with medical care providers to collaborations with other providers such as mental health professionals.
Not surprisingly, these discrepancies of having positive educational experiences related to general and oral health issues but less positive experiences related to mental health issues were correlated with and reflected in the degrees to which especially the third- and fourth-year students reported feeling prepared to communicate with patients and with health care providers from another discipline. Again, the fourth-year dental students said they felt very well prepared to talk with patients and health care professionals from another discipline about oral and systemic health issues and even about diet-related matters; however, they reported feeling significantly less well prepared to talk with them about mental health concerns. Given the severe oral health-related consequences that not just EDs ${ }^{1}$ but other mental health issues ${ }^{12}$ such as depression ${ }^{27}$ and addictions ${ }^{28,29}$ can have on patients' oral health, it may be crucial to provide IPC-related education in regard to these mental health concerns.

While the students' mental health/ED-related educational and preparedness responses were not optimal even for the fourth-year students, respondents in all four cohorts agreed strongly that EDs were a complex phenomenon, that dental professionals should be involved in identifying patients with EDs, and that they personally would be very likely to consider a patient's ED history when determining oral health risk factors. Again, the better students 
were prepared to communicate with these patients and other health care providers about these issues, the more positive their attitudinal responses were.

One additional interesting finding that deserves attention is the fact that the more family members from other health professions the students had, the more positively they evaluated their classroom- and clinic-based education on these topics and the better prepared to communicate they felt. It is possible that having had years of contact with health care providers from other disciplines in an informal familial setting could have sensitized these students to paying increased attention to educational interventions related to IPC and EDs/mental health-related issues. Merely volunteering in a medical and or mental health setting, however, did not have such an effect. This finding raises the question of which other context variables might affect future dentists' knowledge, attitudes, and ultimately motivation to engage in providing care for patients with EDs or other mental health issues in an IPC context. The students' own experiences or their experiences with family members or close friends with EDs or other mental health concerns could play a role in this context. Future research should not only explore these possible connections, but also investigate whether extensive exposure of dental students to patients with EDs and other mental health issues and opportunities to communicate with these patients could provide a basis for more informed care and commitment to providing care for these patients.

This study had several limitations. First, while an expert panel of specialists in oral medicine, academic affairs, interprofessional education, health psychology, and survey research and a senior dental student contributed substantially to ensuring that the survey had content validity, no pilot test with dental students from all four dental classes was conducted. Future research should include such a pilot test. Second, only approximately 600 predoctoral students from about one-third of the 65 dental schools responded to this survey. Given this relatively low number of respondents, generalizations of these findings should be made with caution, because it is possible that students with a stronger interest in EDs and/or IPC may have been more likely to respond. If this were the case, students in general may have less positive attitudes. Third, some students responded to paper and pencil surveys and some to web-based surveys. The fact that the average responses of the ten D4 students at the home school who provided web-based responses and the 68 D4 students at the home school who provided paper and pencil responses did not differ for 47 of the 48 items could be interpreted as support for combining all data. However, using one common answer format would have been preferable. Fourth, while the 339 responses from our home school represented a $77 \%$ response rate, the response rates for the other 21 schools could not be computed, but it is certain that those response rates were considerably lower. Collaborating with specific faculty members at other schools might provide a broader response basis in future research studies. Fifth, dental hygienists are key members of the oral health care team and have ideal opportunities to address potential signs of EDs with patients. ${ }^{13,14,30}$ Future research should explore the research questions in our study in the context of dental hygiene education. Finally, a limitation of this study is that it asked only about students' ED- and IPC-related educational experiences, perceptions, and attitudes. Future research should analyze whether recent graduates carry a positive IPC-related attitude into their actual professional activities.

\section{Conclusion}

Overall, the responding dental students in this study perceived their educational experiences related to oral and systemic health-related IPC rather positively, while their perceptions of their mental health/ ED- and IPC-related educational experiences were less positive. Their perceptions of the extent of these educational experiences correlated significantly with the students' perceived preparedness to communicate with patients and providers from other health care fields about these issues. In contrast, responses from students in all four years of the dental curriculum showed that they viewed EDs as multifaceted issues and agreed that oral health care providers should be involved in the identification of patients with EDs and that a history of EDs should be considered a risk factor for oral disease. Positive correlations existed between these students' perceptions of preparedness to communicate with patients and other providers and not only their perceptions of their ED- and IPCrelated education but also their attitudes towards dentists' involvement in ED-related care, perceptions of other health care professionals' investment in patient health, and self-reported likelihood to engage in IPC considerations. While previous volunteer activities in medical/mental health settings were not related to these students' ED- and IPC-related perceptions, having family members from non-dental health professions was significantly related with more positive 
perceptions of educational experiences and preparedness. A future longitudinal study investigating dental professionals' educational experiences and their actual professional behavior after graduation could be exceptionally useful in fully understanding the effects of IPE on IPC for patients with EDs.

\section{Acknowledgments}

We want to thank the academic deans who forwarded our recruitment email to their dental students and the students who took time to respond to these surveys.

\section{REFERENCES}

1. Lo Russo L, Campisi G, Di Fede O, et al. Oral manifestations of eating disorders: a critical review. Oral Dis 2008;14(6):479-84.

2. DeBate RD, Severson HH, Cragun D, et al. Randomized trial of two e-learning programs for oral health students on secondary prevention of eating disorders. J Dent Educ 2014;78(1):5-15.

3. Neumark-Sztainer D, Wall M, Haines J, et al. Shared risk and protective factors for overweight and disordered eating in adolescents. Am J Prev Med 2007;33(5):359-69.

4. Newmark-Sztainer D, Wall M, Guo J, et al. Obesity, disordered eating, and eating disorders in a longitudinal study of adolescents: how do dieters fare 5 years later? J Am Diet Assoc 2006;106(4):559-68.

5. Haines J, Neumark-Sztainer D. Prevention of obesity and eating disorders: a consideration of shared risk factors. Health Educ Res 2006;21(6):770-82.

6. Neumark-Sztainer D, Hannan P. Weight-related behaviors among adolescent girls and boys: results from a national survey. Arch Pediatr Adolesc Med 2000;154(6):567-77.

7. Litmanen J, Fröjd S, Marttunen M, et al. Are eating disorders and their symptoms increasing in prevalence among adolescent population? Nord J Psychiatry, 14 Sept. 2016; epub ahead of print.

8. Hoek HW. Incidence, prevalence, and mortality of anorexia nervosa and other eating disorders. Curr Opin Psychiatry 2006;19(4):389-94.

9. Suokas JT, Suvisaari JM, Grainger M, et al. Suicide attempts and mortality in eating disorders: a follow-up study of eating disorder patients. Gen Hosp Psychiatry 2014;36(3):355-7.

10. Hoek HW. Review of the worldwide epidemiology of eating disorders. Curr Opin Psychiatry 2016;29(6):336-9.

11. Mehler PS, Brown C. Anorexia nervosa: medical complications. J Eat Disord 2015;3(11).

12. Clark DB. Mental health issues and special care patients. Dent Clin North Am 2016;60(3):551-66.

13. Goldie MP. The oral health care professional's role in the assessment and treatment of eating disorders. Int J Dent Hyg 2006;4(1):52-4.
14. Clark DB. Patients with eating disorders: challenges for the oral health professional. CJDH 2010;44(4):163-70.

15. Aranha AC, Eduardo CP, Cordas TA. Eating disorders part II: clinical strategies for dental treatment. J Contemp Dent Pract 2008;9(7):89-96.

16. DeBate RD, Tedesco LA, Kerschbaum WE. Knowledge of oral and physical manifestations of anorexia and bulimia nervosa among dentists and dental hygienists. J Dent Educ 2005;69(3):346-54.

17. DeBate RD, Severson H, Zwald ML, et al. Development and evaluation of a web-based training program for oral health care providers on secondary prevention of eating disorders. J Dent Educ 2009;73(6):718-29.

18. Mitchell SL, Klein J, Maduramente A. Assessing the impact of an eating disorders treatment team approach with college students. Eat Disord 2015;23(1):45-59.

19. DeBate RD, Tedesco LA. Increasing dentists' capacity for secondary prevention of eating disorders: identification of training, network, and professional contingencies. J Dent Educ 2006;70(10):1066-75.

20. Johansson AK, Nohlert E, Johansson A, et al. Dentists and eating disorders: knowledge, attitudes, management, and experience. Swed Dent J 2009;33(1):1-9.

21. Commission on Dental Accreditation. Accreditation standards for dental education programs. 2016. At: www. ada.org/ /media/CODA/Files/pde.pdf?la=en. Accessed 10 Oct. 2016.

22. Formicola AJ, Andrieu SC, Buchanan JA, et al. Interprofessional education in U.S. and Canadian dental schools: an ADEA team study group report. J Dent Educ 2012;76(9):1250-68.

23. Wilder RS, Bell KP, Phillips C, et al. Dentists' practice behaviors and perceived barriers regarding oral-systemic evidence: implications for education. J Dent Educ 2014;78(9):1252-62.

24. Paquette DW, Bell KP, Phillips C, et al. Dentists' knowledge and opinions of oral-systemic disease relationships: relevance to patient care and education. J Dent Educ 2015;79(6):626-35.

25. American Student Dental Association. U.S. dental schools. 2016. At: www.asdanet.org/us-dental-schools.aspx. Accessed 10 Oct. 2016.

26. Keselyak N, Simmer-Beck M, Bray K, et al. Evaluation of an academic service-learning course on special needs patients for dental hygiene students: a qualitative study. J Dent Educ 2007;71(3):378-92.

27. McFarland M, Inglehart M. Depression, self-efficacy, and oral health: an exploration. Oral Health Dent Manag 2010;9(4):214-22.

28. O'Sullivan EM. Dental health of Irish alcohol/drug abuse treatment center residents. Community Dent Health 2012;29(4):263-7.

29. Rommel N, Rohleder NH, Koerdt S, et al. Sympathomimetic effects of chronic methamphetamine abuse on oral health: a cross-sectional study. BMC Oral Health 2016;16(1):59.

30. Darby ML, Walsh M. Dental hygiene: theory and practice. $4^{\text {th }}$ ed. St. Louis: Saunders, 2014. 